\title{
Nonhistone Lysine Methylation in the Regulation of Cancer Pathways
}

\author{
Scott M. Carlson and Or Gozani \\ Department of Biology, Stanford University, Stanford, California 94305 \\ Correspondence: scottmc@stanford.edu; ogozani@stanford.edu
}

Proteins are regulated by an incredible array of posttranslational modifications (PTMs). Methylation of lysine residues on histone proteins is a PTM with well-established roles in regulating chromatin and epigenetic processes. The recent discovery that hundreds and likely thousands of nonhistone proteins are also methylated at lysine has opened a tremendous new area of research. Major cellular pathways involved in cancer, such as growth signaling and the DNA damage response, are regulated by lysine methylation. Although the field has developed quickly in recent years many fundamental questions remain to be addressed. We review the history and molecular functions of lysine methylation. We then discuss the enzymes that catalyze methylation of lysine residues, the enzymes that remove lysine methylation, and the cancer pathways known to be regulated by lysine methylation. The rest of the article focuses on two open questions that we suggest as a roadmap for future research. First is understanding the large number of candidate methyltransferase and demethylation enzymes whose enzymatic activity is not yet defined and which are potentially associated with cancer through genetic studies. Second is investigating the biological processes and cancer mechanisms potentially regulated by the multitude of lysine methylation sites that have been recently discovered.

ysine methylation is the addition of one, two, Lor three methyl groups to the $\varepsilon$-nitrogen of a lysine sidechain (Fig. 1). Methylation is generated by lysine methyltransferase enzymes (KMTs) and removed by lysine demethylases (KDMs). Lysine methylation was first described in 1959 by R.P Ambler and M.W. Rees on a Salmonella typhimurium flagellar protein (Ambler and Rees 1959). Lysine methylation in mammals was first reported 5 years later when Kenneth Murray (1964) found methylated lysine on bovine histone proteins. Over the next few years lysine methylation was found on a variety of other proteins (Paik et al. 2007). The biological purpose of lysine methylation remained enigmatic for several decades and it was only in the first decade of this century that an understanding began to emerge of how lysine methylation contributes to regulation of processes, including epigenetics, chromatin function, and cellular signaling.

Most research on lysine methylation has focused on histone methylation because of its early discovery and clear importance in chromatin biology and gene regulation. Thomas Jenuwein and colleagues found that the human enzyme

Editors: Scott A. Armstrong, Steven Henikoff, and Christopher R. Vakoc

Additional Perspectives on Chromatin Deregulation in Cancer available at www.perspectivesinmedicine.org

Copyright (C) 2016 Cold Spring Harbor Laboratory Press; all rights reserved; doi: 10.1101/cshperspect.a026435

Cite this article as Cold Spring Harb Perspect Med 2016;6:a026435 
S.M. Carlson and O. Gozani

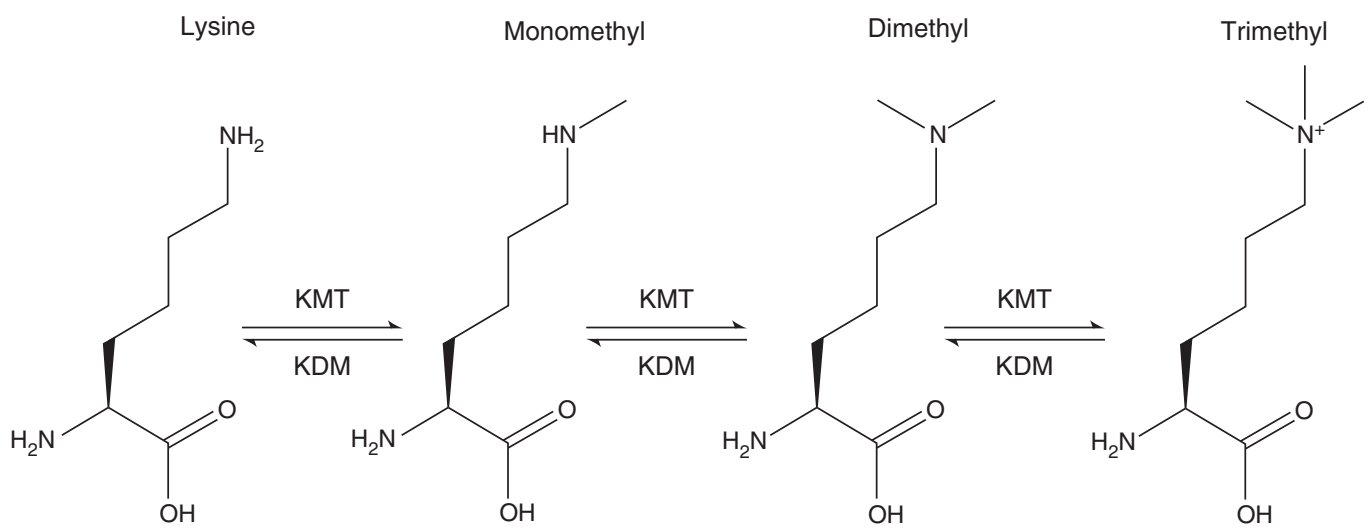

Figure 1. Lysine residues can be modified by the addition of up to three methyl groups at the $\epsilon$-nitrogen. Lysine methylation is catalyzed by lysine methyltransferase enzymes (KMTs) and removed by lysine demethylase enzymes (KDMs). Methylation states of lysine are recognized by protein "reader domains" that bind to specific methyl or nonmethyl states of their target proteins.

SUV39H1 is able to methylate histone $\mathrm{H} 3$ at lysine 9 (H3K9) (Rea et al. 2000). The next year the groups of Thomas Jenuwein and Tony Kouzarides independently discovered that the chromodomain of HP1 is a methyllysine "reader domain" able to suppress transcription by selectively binding to methylated H3K9 (Bannister et al. 2001; Lachner et al. 2001). The first lysine demethylase enzyme was discovered in 2004 by the group of Yang Shi (Shi et al. 2004). The combination of enzymes to "write" and "erase" methylation with proteins that can "read" methylation of their interacting partners established lysine methylation as a dynamic signaling process similar in principle to phosphorylation.

Many KMTs, KDMs, and reader domains have now been identified that act on or recognize histone proteins (Black et al. 2012). A smaller number of enzymes have been identified with the ability to methylate lysine on nonhistone proteins, although lysine methylation has been established as an important player in cellular signaling processes (see Biggar and Li 2015 for a detailed history). Similar to its role on histones, the primary function of nonhistone lysine methylation is to regulate protein-protein interactions. Such interactions control a wide range of downstream processes such as protein stability, subcellular localization, and DNA binding (Hamamoto et al. 2015). It is not yet known whether the same protein domain families that recognize histone lysine methylation are also responsible for reading nonhistone lysine methylation events, or whether there are yet to be discovered families that recognize nonhistone lysine methylation.

Until recently, research into nonhistone lysine methylation was limited because there were no strategies to identify lysine methylation across the entire proteome. Starting in 2013, we and several other groups developed techniques to identify methylated proteins across the entire proteome. We recently reviewed these techniques (Carlson and Gozani 2014) and they will be discussed in more detail later in the text. These proteomic studies have identified many hundreds of new methylated proteins and methylated lysine residues, but there is little known about the functional relevance of these modifications, the enzymes responsible for generating these methylation events, and the potential roles for nonhistone lysine methylation in cancer or other diseases. However, a striking number of methylated proteins have been discovered in pathways related to oncogenesis and cancer progression. We will discuss one example of nonhistone lysine methylation regulating growth pathways central to cancer and examine some of the other cancer pathways potentially regulated by lysine methylation. 
Herein we will review the nonhistone KMT and KDM enzymes associated with cancer, and we will discuss what is currently known about the molecular mechanisms underlying these associations. In the rest of the article, we will focus on areas of ongoing and future research. In particular, we will highlight cancer-associated KMTs and KDMs that lack known enzymatic functions and lysine methylation in cancer pathways where the possibility of a regulatory function has not yet been investigated.

\section{SET DOMAIN ENZYMES IN CANCER}

There are two proteins families known to methylate lysine: SET domain family and the seven $\beta$-strand enzymes ( $7 \beta$-strand enzymes). Most research has focused on the SET domain family, which includes about 55 human proteins (named for three Drosophila proteins originally recognized to contain the domain: $\mathrm{Su}$ (var)3-9, enhancer of zeste, trithorax) (Petrossian and Clarke 2011). The human genome encodes approximately 125 members of the $7 \beta$-strand family (Petrossian and Clarke 2011). Different members of the $7 \beta$-strand family are able to methylate a wide range of substrates, including lysine, arginine, other amino acid side chains,
DNA, RNA, metabolites, and arsenic (Schubert et al. 2003). The 7 $\beta$-strand family is discussed later in the chapter.

Most research into SET domain proteins has focused on their role in methylating histones. This seems to be the primary activity for about a third of the family. A smaller number target both histones and nonhistone proteins, and a few characterized enzymes are likely to act primarily on nonhistone substrates (Fig. 2). Close to half of the SET domain proteins have no known substrates and it is not clear whether they have enzymatic activity at all.

Experimental evidence for the activity of many SET domain proteins is incomplete, making it difficult to sort them by activity on histones or nonhistone substrates. One challenge comes from nonspecific activity when these enzymes are expressed as isolated proteins and probed for activity on candidate substrates. Many enzymes will methylate recombinant substrates in vitro, which are not substrates in a natural context. This is especially true of histone proteins because their tail regions contain many lysine residues that are excellent substrates for some of the commonly characterized KMTs. Thus, some SET domain proteins will methylate free histones but have little or no activity on

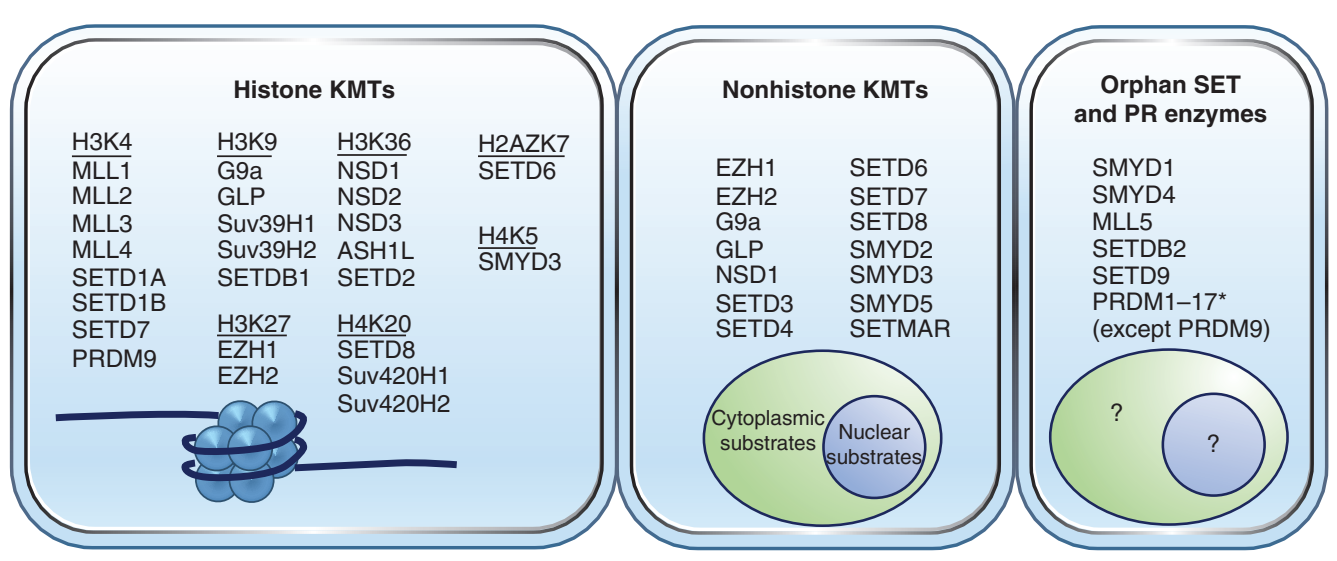

Figure 2. SET domain proteins categorized by their established substrate specificity for (1) histone proteins, (2) nonhistone proteins, or (3) orphan enzymes with no well-established enzymatic activity. Note that there are enzymes that are primarily histone lysine methyltransferase enzymes (KMTs) but also have reported nonhistone substrates. In addition, there are proteins that are primarily nonhistone KMTs, with reports of histone methylation activity. We note that several PRDMs (e.g., 1, 2, 3, and 16) have been reported to have activity on H3K9 and more work is needed to understand the catalytic activities of these enyzmes. 
histones packaged into nucleosomes that contain a full histone octomer wrapped with DNA (the physiologic context in which histones commonly exist) (Levy et al. 2011; Carlson et al. 2015). Other enzymes methylate many sites on free histones but become specific for a single residue when presented with nucleosome substrates (our unpublished observations). We anticipate that an in vitro activity seen only on free histones but not nucleosomes needs to be carefully interpreted and rigorously evaluated in cell culture to conclude that it is physiologic. Similarly, many SET domain enzymes have nonspecific activity on nonhistone substrates in vitro so candidate nonhistone substrates need to be supported by extensive characterization in cell culture.

A second challenge is overinterpretation of data from Western blotting with methyl-specific antibodies. These antibodies are often incompletely characterized or else bind nonspecifically to other methylated residues, methylation on other proteins, other methylation states (e.g., trimethyl instead of dimethyl), or other posttranslational modifications of lysine (Fuchs et al. 2011). This is especially true when candidate KMT substrates contain multiple methylated residues, or when the methylation state being probed is much less abundant than other methyl marks, a frequent issue when analyzing histone modifications.

To frame the discussion of nonhistone KMTs in cancer, we have consolidated evidence from literature reports as well as unpublished experiments in our own laboratory to sort the SET domain enzymes into enzymes that are well established to act (1) on histones, (2) on nonhistone substrates, or else (3) are "orphans," which have no activity that has been widely observed-we note that there are some enzymes that are present in both the first and second groups (Fig. 2). With regard to the orphan SET domains, they may not be enzymatic, may only be active in the presence of other unidentified factors, or may target substrates that have not been identified. In some cases there are individual reports of enzymatic activity that await independent corroboration and for the sake of caution we have included them as orphans.
These and other orphan KMTs are discussed later in the text. The literature is too extensive on the topic to cite it thoroughly here; in lieu we refer to excellent reviews of SET domain activities (Dillon et al. 2005; Herz et al. 2013).

\section{MOLECULAR MECHANISMS OF SET DOMAIN NONHISTONE METHYLATION IN CANCER}

It is beyond the scope of this article to discuss all the nonhistone KMTs that touch on pathways involved in cancer. Comprehensive reviews of nonhistone lysine methylation have recently been provided by Nakamura and colleagues (Hamamoto et al. 2015) and Biggar and Li (2015). Here we will focus on establishing a framework to understand KMTs and their role in cancer. With this in mind, we will discuss two examples of nonhistone KMTs with clear roles in cancer. First is SMYD3, a primarily cytoplasmic enzyme that cooperates with active oncogenic K-Ras to regulate growth signaling in lung and pancreatic carcinomas and likely other types of cancer. Second is the pair of enzymes G9a and GLP, closely related KMTs that are strongly associated with cancer progression and metastasis. These enzymes methylate both histone and nonhistone substrates, which raises important questions about how to discern the biological and pathologic role of these activities. Other nonhistone KMTs that affect cancer pathways will be discussed briefly and we will finish the section by reviewing the orphan SET domain proteins that are strongly associated with cancer.

\section{SMYD3: A Cytoplasmic KMT that Promotes Ras-Driven Cancer Pathways}

SMYD3 was first identified based on an expressed sequence tag that was overexpressed in colorectal and hepatocellular carcinomas (Hamamoto et al. 2004). It was grouped into the SMYD family based on its combination of its split SET and zf-MYND domains. Its cancer relevance was quickly established based on its ability to enhance growth of NIH3T3 fibroblasts. Since the initial report, overexpression 
of SMYD3 has been found in many other types of cancer, especially those carrying mutations in K-Ras that lead to constitutively active growth signaling (Hamamoto et al. 2004; Gaedcke et al. 2010; Watanabe et al. 2011). The link to K-Ras is clinically important because mutations in the $\mathrm{K}$-Ras gene occur in more than half of all human cancers (Forrester et al. 1987; Prior et al. 2012). K-Ras itself has been the target of extensive efforts to develop targeted inhibitors but the protein itself remains difficult to target directly with pharmacological treatments (McCormick 2015).

SMYD3 was initially described as an enzyme that generates trimethylation of histone $\mathrm{H} 3$ at lysine 4 (H3K4me3), a hallmark of active transcription (Hamamoto et al. 2004). However, subsequent work has shown that SMYD3 has no detectable activity on H3K4 (Van Aller et al. 2012; Mazur et al. 2014). SMYD3 does methylate histones, specifically histone $\mathrm{H} 4$ at lysine 5 (H4K5) in vitro, and SMYD3 knockdown reduced $\mathrm{H} 4 \mathrm{~K} 5$ methylation in cell culture, although H4K5me is a very lowly abundant species of histone modification (Van Aller et al. 2012). Indeed, SMYD3 largely resides in the cytoplasm and the first evidence that SMYD3 acts on nonhistone proteins was reported by Furukawa and colleagues in 2007 (Kunizaki et al. 2007). They found that SMYD3 methylates vascular endothelial growth factor receptor 1 (VEGFR1) both in vitro and when the proteins are overexpressed in cell culture. VEGFR1 methylation increased its kinase activity, although the molecular mechanism for this is not known. In addition, whether this methylation event is linked to cell growth or cancer progression has yet to be determined.

SMYD3 was recently shown to trimethylate the kinase MAP3K2 (Mazur et al. 2014). MAP3K2 is one of several kinases within the $\mathrm{K}$-Ras-regulated mitogen-activated protein kinase-signaling cascade (MAPK pathway) that regulates cell growth. MAPK pathways are composed of a three-kinase signaling cascade, where each kinase in the pathway becomes activated, then phosphorylates and activates the next kinase down. The pathway is deactivated when these kinases are dephosphorylated by a phos- phatase. One mechanism by which oncogenic mutations in K-Ras and other Ras genes promote cancer is through activation of a MAPK pathway leading to activation of the kinases ERK1 and ERK2. Activated ERK1 and ERK2 phosphorylate a wide range of effector proteins, and especially transcription factors, that contribute to proliferation, cell survival, and metastasis (Plotnikov et al. 2011).

The methylation of MAP3K2 by SMYD3 was shown to promote activation of ERK1/2 in mouse models of Ras-driven pancreatic and lung adenocarcinoma. The methylation event does not intrinsically affect the kinase activity of MAP3K2 and rather prevents the protein phosphatase 2A complex (PP2A) from binding to $\mathrm{MAP} 3 \mathrm{~K} 2$. $\mathrm{PP} 2 \mathrm{~A}$ regulates the MAPK cascade by dephosphorylating and inactivating kinases in the cascade. The interaction with PP2A explains how SMYD3 cooperates with mutant KRas to promote cancer. In this model SMYD3 relieves repression by $\mathrm{PP} 2 \mathrm{~A}$ and increases mutant K-Ras signaling to drive inappropriate growth signals through the MAPK cascade. Chemical inhibition of PP2A phenocopies overexpression of SMYD3 in lung and pancreatic cancer cell and xenograft models, suggesting that this is important mechanism by which SMYD3 promotes these cancers.

MAP3K2 is not highly expressed in all types of cancers, all cancers that carry K-Ras mutations, or even all cancers that overexpress SMYD3. It is, therefore, likely that SMYD3 acts through different mechanisms depending on the cellular context and it will be important to elucidate the relevant substrates in other cancers regulated by SMYD3. Establishing how SMYD3 contributes to other types of cancer is an important area for future study.

\section{G9a and GLP: Coassociated Mixed Histone/ Nonhistone KMTs that Promote Cancer}

G9a (also called EHMT2) was discovered in 2001 as a "hyperactive" methyltransferase enzyme able to mono- and dimethylate lysines 9 and 27 of histone H3 (Tachibana et al. 2001). G9a and the closely related enzyme G9a-like protein (GLP) are responsible for the bulk of 
H3K9 dimethylation (H3K9me2) in human cells (Tachibana et al. 2002, 2005). These enzymes are crucial for early development and high G9a expression is associated with aggressive cancer, metastasis, and poor prognosis in cancers of the breast, lung, head and neck, brain, and ovaries among others (Casciello et al. 2015).

The potential importance of G9a in so many types of cancer led in part to development of the inhibitor BIX-01294 (Kubicek et al. 2007). Treatment with this inhibitor blocked epithelial-to-mesenchymal transition in cell culture and in in vivo models of breast cancer (Dong et al. 2012), and reduced proliferation rates of some leukemia cell lines (Savickiene et al. 2014). BIX01294 causes significant cellular toxicity separate from its function inhibiting G9a and GLP, limiting its usefulness in preclinical research. Improved inhibitors UNC0638, BRD4770, UNC0642, and A-366 have now achieved cellular toxicity, target specificity, and pharmacokinetics that are suitable for animal studies (Vedadi et al. 2011; Yuan et al. 2012; Liu et al. 2013a; Sweis et al. 2014).

In cells G9a and GLP are responsible for a large fraction of all the $\mathrm{H} 3 \mathrm{~K} 9 \mathrm{mel}$ and H3K9me2. H3K9me2 can be bound by a number of reader domain-containing proteins that are linked to transcriptional repression, such as the HP1 proteins, G9a and GLP themselves, and others (Yun et al. 2011). Transcriptional repression through $\mathrm{H} 3 \mathrm{~K} 9 \mathrm{me} 2$ is certainly an important function of G9a and GLP but these enzymes are also able to methylate a variety of nonhistone proteins.

The first example of G9a acting as a nonhistone KMTwas shown by the group of Alexander Tarakhovsky in 2007 (Sampath et al. 2007). They reported an automethylation site on G9a, which, like H3K9me2, is bound by HP1 and potentially contributes to silencing chromatin. In 2008 Jeltsch and colleagues used peptide arrays to identify additional candidate nonhistone substrates for G9a, and verified that several of these can be methylated by G9a in cells (CDYL1, WIZ, ACINUS, and confirmed G9a itself) (Rathert et al. 2008). Since then, many additional nonhistone substrate for G9a have been reported, suggesting that it has important functions modifying both histone and nonhistone proteins, although the biological role of nonhistone substrates is not well understood (Shinkai and Tachibana 2011). These enzymes are extremely promiscuous in vitro and overexpressed enzymes may not be properly targeted in cell culture, making it difficult to determine which substrates contribute to their physiological effects. Further research using G9a inhibitors, genetic perturbations, or cell-based chemical biology will be important to identify or validate physiological targets for these and other enzymes (we recently reviewed these approaches in detail (Carlson and Gozani 2014)).

One nonhistone G9a substrate clearly linked to cancer is the tumor suppressor p53. G9a and GLP methylate p53 at lysine 373 (Huang et al. 2010). The function of this methylation site is not known but methylation appears to be reduced during repair of DNA damage, suggesting that it may limit p53 activity. Indeed, the first example of a histone KMT with dual activity was shown by Reinberg and colleagues, who showed that SETD7 monomethylates p53 at $\mathrm{K} 372$ to positively regulate $\mathrm{p} 53$ protein stability (Chuikov et al. 2004). The methyltransferase enzymes SMYD2 and SETD8 also target p53 at other lysine residues (Huang et al. 2006; Shi et al. 2007). With many KMTs targeting p53, it is clear that lysine methylation has an important role in coordinating the tightly regulated response of p53 to genotoxic stress. Our understanding of methylation events on p53 has been reviewed in detail elsewhere (Huang and Berger 2008; West and Gozani 2011).

G9a and GLP have another feature that shows the role of reader domains in methylation signal transduction. Both proteins include an ankyrin repeat domain that binds specifically to mono- and dimethylated lysine (Collins et al. 2008). A major target for this activity is histone $\mathrm{H} 3 \mathrm{~K} 9 \mathrm{me} 2$. There are several proposed functions for G9a/GLP binding to their own enzymatic product. It may serve to protect the modification from conversion to trimethylation or from demethylation (Collins and Cheng 2010). Alternatively, recent evidence indicates that $\mathrm{H} 3 \mathrm{~K} 9$ methylation promotes similar meth- 
ylation at adjacent nucleosomes (Liu et al. 2015). This would establish positive feedback allowing H3K9me2 to "spread" along a chromatin until it encounters opposing regulatory processes that establish a boundary between regulatory regions. Finally, this binding event can help maintain chromatin regions containing $\mathrm{H} 3 \mathrm{~K} 9 \mathrm{me} 2$ on DNA replication (Margueron and Reinberg 2010).

In addition to recognizing histones, the ankryin repeats are able to bind to methylated nonhistone proteins. Specifically, the NF- $\mathrm{B}$ transcription factor RelA is methylated by SETD6, which creates a docking site recognized by the ankryin repeats of GLP (Levy et al. 2011). This brings GLP to NF- $\mathrm{B}$ target genes where it represses gene activity by methylating $\mathrm{H} 3 \mathrm{~K}$. Understanding the roles of histone and nonhistone binding for these and other methyllysine reader domains is a crucial and exciting area for ongoing research.

\section{Other SET Domain Enzymes Affecting Cancer Pathways}

There are several enzymes with intriguing links to cancer or cancer cell phenotypes in which specific enzyme/substrate relationships in this disease have yet to be elucidated. For example, the enzyme SMYD2 is overexpressed in several types of cancer and associated with poor clinical prognoses (Komatsu et al. 2009; Sakamoto et al. 2014). SMYD2 is a promiscuous enzyme in vitro and it is often referred to as a histone KMT based on its robust in vitro activity on recombinant histone substrates. The enzyme has many reported nonhistone substrates that have been validated in cell culture and could be relevant in cancer, including the tumor suppressors $\mathrm{p} 53, \mathrm{Rb}$ and PTEN, protein-folding chaperone HSP90, and estrogen receptor $\alpha$ (Huang et al. 2006; Abu-Farha et al. 2011; Cho et al. 2012; Zhang et al. 2013; Nakakido et al. 2015).

SETD6, SETD7, SETD8, and SETMAR are all SET domain enzymes that do not appear to act directly as oncogenes or tumor suppressors but which methylate proteins involved in cancer pathways. SETD6 targets the RelA subunit of the transcription factor NF- $\kappa$ B to regulate inflam- mation (Levy et al. 2011); SETD7 has many cancer-associated substrates, including p53, the DNA methyltransferase DNMT1, the phosphatase PPP1R12A, which regulates cell cycle through $\mathrm{Rb}$, and many others (Pradhan et al. 2009); SETD8 methylates histone H4 as well as p53 and proliferating cell nuclear antigen (PCNA) (Nishioka et al. 2002; Shi et al. 2007; Takawa et al. 2012); SETMAR is involved in repairing DNA damage and methylates the splicing factor snRNP70 (Fnu et al. 2011; Carlson et al. 2015).

\section{Orphan SET Domain Proteins Associated with Cancer}

Many other SET domain proteins do not have known molecular catalytic activity but are still associated with cancer through genome or exome sequencing, experiments in cell culture, or experiments in animal models. Table 1 lists these proteins and selected major associations with cancer. It may be that these proteins are pseudoenzymes and instead work through nonenzymatic mechanisms, such as binding DNA or by protein interactions. There are clear examples of KMT proteins with nonenzymatic functions, including KMTs expressed as isoforms lacking their catalytic domain or else truncated by chromosomal rearrangement. For example, acute myeloid leukemia is frequently driven by translations involving the MLL gene truncated so that it lacks the catalytic SET domain (McCabe et al. 1992; Meyer et al. 2013). Similarly, an isoform of NSD3 that lacks the SET domain has recently been shown to act by bridging a protein interaction between histones and other chromatin-associated proteins (Shen et al. 2015). With all of the hundreds of lysine methylation sites recently discovered across the proteome, we expect that many of these enzymes have still unknown activity as nonhistone KMTs and we simply have not developed the right tools and methods to characterize many of these orphan enzymes.

The PRDM subfamily deserves to be highlighted as a major area for future research. These 17 human proteins contain an amino-terminal SET domain and a variable number of carboxy- 
S.M. Carlson and O. Gozani

Table 1. Examples of selected "orphan" SET domain proteins associated with cancer

\begin{tabular}{llcc}
\hline Enzyme & \multicolumn{1}{c}{ Selected cancer associations } & Enzyme & Selected cancer associations \\
\hline SMYD4 & $\begin{array}{c}\text { Deleted/silenced in medulloblastoma } \\
\text { (Northcott et al. 2009) }\end{array}$ & PRDM5 & $\begin{array}{c}\text { Silenced in gastric cancer } \\
\text { (Watanabe et al. 2007) }\end{array}$ \\
PRDM1 & $\begin{array}{c}\text { Deleted in diffuse large B-cell lymphoma } \\
\text { (Pasqualucci et al. 2006) }\end{array}$ & PRDM11 & $\begin{array}{c}\text { Deleted or silenced in diffuse } \\
\text { large B-cell lymphoma (Fog } \\
\text { et al. 2015) }\end{array}$ \\
PRDM2 & $\begin{array}{c}\text { Silenced in diverse solid tumors (Du et al. } \\
\text { (RIZ1) }\end{array}$ & PRDM14 & $\begin{array}{c}\text { Overexpressed in breast cancer } \\
\text { (Hu et al. 2005; Nishikawa }\end{array}$ \\
PRDM3 & Chromosomal rearrangement in & & et al. 2007) \\
(MECOM, & myelodysplastic syndrome and myeloid & & \\
MDS1/EVI1) & leukemia (Morishita et al. 1992) & & \\
\hline
\end{tabular}

terminal zinc fingers (Fog et al. 2012). The SET domain is often called a PR or PR/SET domain because it diverges significantly from the other SET domain proteins. So far, only PRDM9 is clearly shown to have enzymatic activity, having the greatest activity on $\mathrm{H} 3 \mathrm{~K} 4$ and lower activity on $\mathrm{H} 3 \mathrm{~K} 9$ and $\mathrm{H} 3 \mathrm{~K} 36$ in vitro (Hayashi et al. 2005). The H3K4me3 activity is thought to mark meiotic hotspots and be critical for speciation (Baudat et al. 2010; Myers et al. 2010; Parvanov et al. 2010); whether H3K9 and H3K36 methylation also play a role in these meiosisspecific functions remains to be determined.

Many of the PRDM family proteins have important functions in cellular differentiation and development, and many are frequently deleted, mutated, or overexpressed in cancer (Fog et al. 2012). For example, PRDM1 is a master regulator of terminal $\mathrm{B}$-cell differentiation, and loss of PRDM1 expression has been found in a majority of activated B-cell-like diffuse large B-cell lymphomas (Pasqualucci et al. 2006). Loss of PRDM1 promotes reactivation of the cell cycle in terminally differentiated B cells. Similarly, overexpression of a specific splicing isoform of PRDM2 called RIZ1 acts as a tumor suppressor in cancers of the breast, liver, and colon (Du et al. 2001).

With such central roles in development and disease, identifying methylation substrates or other molecular functions for the PRDM family is a crucial area for future research. There have been reports of histone methylation activity by several PRDM proteins in addition to PRDM9
(Derunes et al. 2005; Eom et al. 2009; Pinheiro et al. 2012); however, structural studies have suggested that these PR/SET domains lack residues necessary for binding to $S$-adenosyl methionine (Wu et al. 2013), the cofactor that donates methyl groups for KMTactivity. Extensive research by several groups, including our own, has failed to establish enzymatic activity for these enzymes. Several groups have found that PRDM proteins are involved in recruitment of other chromatin-modifying factors, suggesting that their function may be independent of any enzymatic activity (Hohenauer and Moore 2012). Except for PRDM9 it is not yet clear whether enzymatic activities attributed to the PRDM family are intrinsic to proteins themselves or if they belong to copurifying enzymes. Another possibility is that PRDM proteins are responsible for methylation of nonhistone substrates that have yet to be identified. Given their involvement in cancer and other diseases it will be important to determine if some or all of the PRDM proteins have intrinsic enzymatic activity, or whether noncatalyic biological functions exist for these PR/SET domains.

\section{7 $\beta$-STRAND ENZYMES: A LARGE AND ENIGMATIC FAMILY ASSOCIATED WITH CANCER}

Members of the $7 \beta$-strand methyltransferase family are the second group of enzymes able to methylate lysine. The best studied of these enzymes, which act on lysine in humans, is DOT1L, 
which methylates histone $\mathrm{H} 3$ at lysine 79 strictly in a nucleosome context ( $\mathrm{Ng}$ et al. 2002). Although DOT1L is the only $7 \beta$-strand enzyme known to methylate a lysine residue on histones, other members of this family are linked to lysine methylation of nonhistone proteins, arginine residues on histone and nonhistone proteins, and nucleic acids (Schubert et al. 2003).

In 2010 Robert Houtz and colleagues discovered that human calmodulin is methylated by a $7 \beta$-strand enzyme now named calmodulin-lysine $N$-methyltransferase (CAMKMT) (Magnani et al. 2010). Soon after, the group of Pål Falnes found that the $7 \beta$-strand enzyme METTL21D (renamed VCPKMT) methylates VCP, an ATPase enzyme (Kernstock et al. 2012). Several groups have since identified additional $7 \beta$-strand enzymes that methylate lysine residues of nonhistone substrates. Although research into $7 \beta$-strand KMTs is progressing quickly, there is still very little about their role in biology or human disease (Cloutier et al. 2013, 2014; Jakobsson et al. 2013; Davydova et al. 2014; Małecki et al. 2015). Dozens of human $7 \beta$-strand enzymes are still entirely uncharacterized and we expect that more of them will turn out to be KMTs.

To understand the potential scope of KMT enzymes in cancer, we reviewed data from The Cancer Genome Atlas (TCGA) to find candidate KMTs that are associated with cancer (Cerami et al. 2012; Gao et al. 2013). We included only enzymes that methylate lysine on nonhistone proteins or else have no known function. Table 2 lists the candidate $7 \beta$-strand KMTs that are most strongly associated with cancer in the TCGA dataset or in studies indexed by the TCGA. This list is subjective and only meant to serve as a guide for future work. Hypothesis-driven research will be needed to determine if any of these enzymes contribute to cancer or present any therapeutic opportunity.

\section{THE LSD1 LYSINE DEMETHYLASE IN CANCER}

The first lysine demethylase (KDM), lysine-specific demethylase 1A (LSD1) was discovered 2004 by Yang Shi and colleagues (Shi et al. 2004). It belongs to the family of FAD-depen- dent monoamine oxidases. LSD1 removes mono- and dimethylation from histone $\mathrm{H} 3 \mathrm{~K} 4$, and under specific circumstances from $\mathrm{H} 3 \mathrm{~K} 9$ (Metzger et al. 2005; Laurent et al. 2015). In 2007, the group of Shelley Berger found that LSD 1 regulates 53 by removing dimethylation from lysine 370, providing the first evidence of reversible lysine methylation on human nonhistone proteins (Huang et al. 2007). Other nonhistone substrates of LSD1 have since been discovered, including E2F1, DNMT1, and MYPT1 (Zheng et al. 2015). Many of these targets belong to pathways that contribute to oncogenesis or tumor suppression, although their individual roles in cancer progression have not been established. LSD2 is another member of the FADdependent monoamine oxidases, which can demethylate histones, but it has not been reported to remove methylation from nonhistone proteins (Black et al. 2012).

LSD1 is frequently overexpressed in cancer, especially of the prostate, bladder, lung, and colon (Shi 2007; Hayami et al. 2011). High LSD1 expression is generally associated with invasive disease and a poor prognosis, and knockdown or inhibition of LSD1 reduces invasive phenotypes in several cell culture systems (Wang et al. 2011). These roles in cancer make LSD1 a promising target for new therapeutics and there has been extensive work on developing small molecule inhibitors of LSD1 (Zheng et al. 2015). In particular, LSD1 inhibition has been shown to sensitize acute myeloid leukemia to treatment with all-trans retinoic acid (Schenk et al. 2012), and phase I clinical trials were initiated in 2014 to exploit this effects (clinicaltrials.gov, identifiers NCT02273102 and NCT02261779). GlaxoSmithKline has also begun phase I clinical trials to test the effect of the LSD1 inhibitor GSK2879552 in small-cell lung cancer and acute myeloid leukemia (clinicaltrials.gov, identifiers NCT02177812 and NCT02034123).

The second family of KDM is the Jumonji C domain (JmjC)-containing enzymes. The first member of this family was JHDM1, discovered by the group of Yi Zhang in 2006 (Tsukada et al. 2006). Several of these enzymes have well-characterized activity on histones both in vitro and in cells (Black et al. 2012). Demethylation of 
S.M. Carlson and O. Gozani

Table 2. Selected uncharacterized $7 \beta$-strand methyltransferase proteins frequently deleted or amplified cancer in datasets from The Cancer Genome Atlas (TCGA)

\begin{tabular}{|c|c|c|c|}
\hline Enzyme & Selected cancer associations & Enzyme & Selected cancer associations \\
\hline \multirow[t]{4}{*}{ FAM86B1 } & Deletion: & METTL11B & Amplification: \\
\hline & Uterine carcinosarcoma & & Bladder urothelial carcinoma \\
\hline & Prostate adenocarcinoma & & Invasive breast carcinoma \\
\hline & Bladder urothelial carcinoma & & Liver hepatocellular carcinoma \\
\hline \multirow[t]{5}{*}{ FAM86B2 } & Deletion: & METTL13 & Amplification: \\
\hline & Uterine carcinosarcoma & & Bladder urothelial carcinoma \\
\hline & Prostate adenocarcinoma & & Liver hepatocellular carcinoma \\
\hline & Bladder urothelial carcinoma & & Pancreatic cancer \\
\hline & & & Lung adenocarcinoma \\
\hline \multirow[t]{5}{*}{ FAM173B } & Amplification: & METTL18 & Amplification: \\
\hline & Lung squamous cell carcinoma & & Bladder urothelial carcinoma \\
\hline & Lung adenocarcinoma & & Liver hepatocellular carcinoma \\
\hline & Bladder urothelial carcinoma & & Breast invasive carcinoma \\
\hline & & & Lung adenocarcinoma \\
\hline \multirow[t]{4}{*}{ FTSJ2 } & Amplification: & METTL21B & Amplification: \\
\hline & Pancreatic cancer & & Sarcoma \\
\hline & Stomach adenocarcinoma & & Glioblastoma \\
\hline & Lung adenocarcinoma & & \\
\hline \multirow[t]{3}{*}{ FTSJ3 } & Amplification: & METTL24 & Deletion: \\
\hline & Breast invasive carcinoma & & Diffuse large B-cell lymphoma \\
\hline & & & Prostate adenocarcinoma \\
\hline \multirow[t]{4}{*}{ KIAA1456 } & Deletion: & TGS1 & Amplification: \\
\hline & Uterine sarcoma & & Metastatic prostate adenocarcinoma \\
\hline & Prostate adenocarcinoma & & Uveal melanoma \\
\hline & Bladder urothelial carcinoma & & Breast invasive carcinoma \\
\hline \multirow[t]{2}{*}{ METTL7A } & Deletion: & THUMPD3 & Amplification: \\
\hline & Adenoid cystic carcinoma & & Bladder urothelial carcinoma \\
\hline \multirow[t]{2}{*}{ METTL7B } & Deletion: & & \\
\hline & Adenoid cystic carcinoma & & \\
\hline
\end{tabular}

nonhistone proteins by the JmjC-family of enzymes has not been well characterized. With hundreds of methylated proteins discovered in recent years, we believe it likely that more nonhistone KDMs will soon be discovered.

\section{CONCLUDING REMARKS: UNDERSTANDING LYSINE METHYLATION ACROSS CANCER PATHWAYS}

Proteomic techniques allow many posttranslational modifications to be routinely identified and measured across hundreds or thousands of proteins. In these approaches, modified proteins or peptides are captured using chemical affinity or immunoprecipitation. Enriched proteins or peptides are then identified using mass spectrometry. Early attempts to analyze the posttranslational "lysine methylome" were limited by the antibodies available to immunoprecipitate methylated lysine (Ong et al. 2004; Ong and Mann 2006).

In 2013, the authors and the group of Shawn Li independently used methyllysine reader domains to enrich and identify methylated proteins (Liu et al. 2013b; Moore et al. 2013). Soon after the group of Ben Garcia and the company Cell Signaling Technologies, each used antimethyl antibodies with broad sequence specificity to perform proteomic studies that identified lysine methylation at hundreds of new sites (Cao et al. 2013; Guo et al. 2014). There are currently 1324 proteins with lysine methylation appearing the PhosphoSitePlus database 

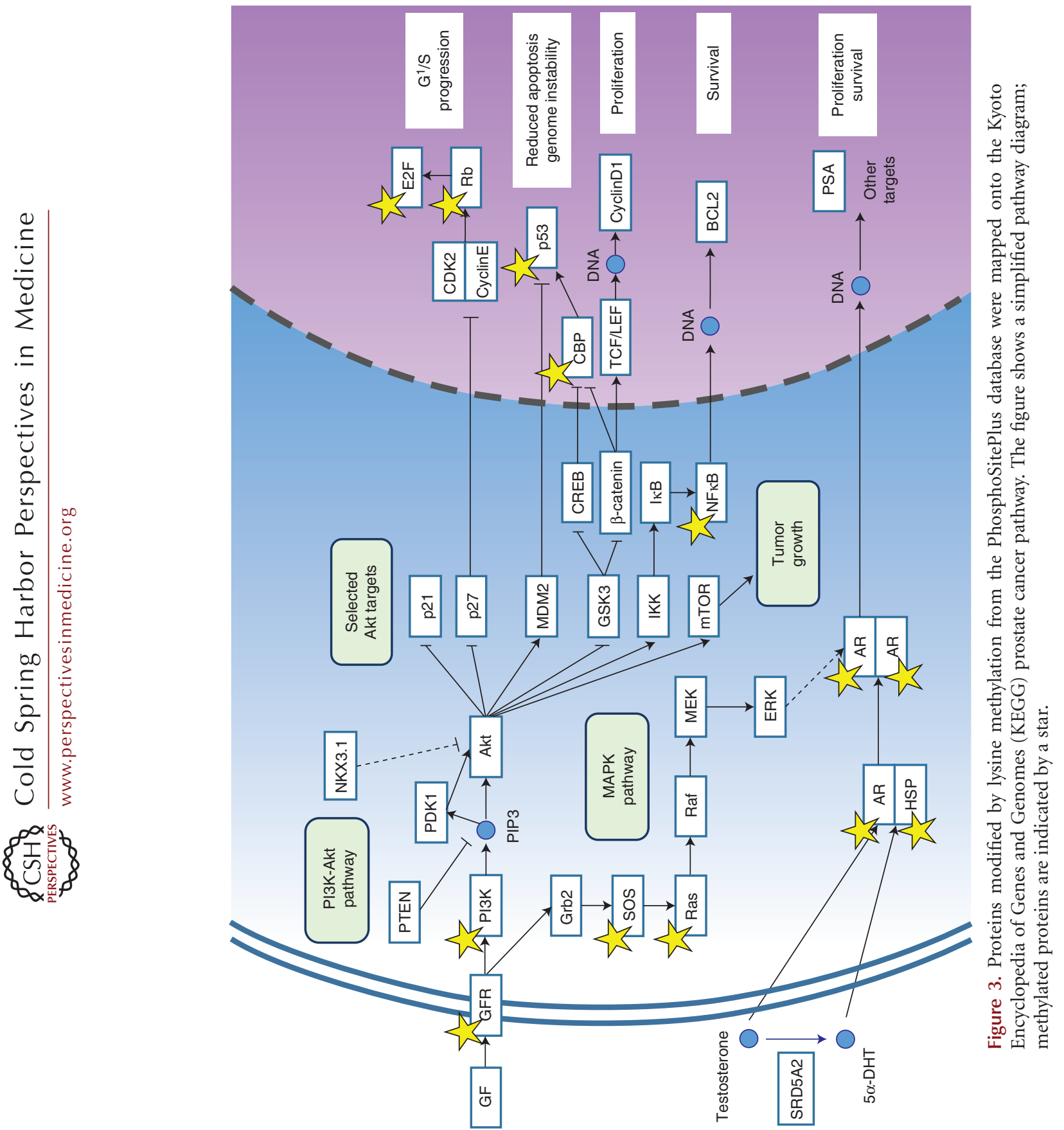
(www.phosphosite.org) (Hornbeck et al. 2012). It is important to be aware that of factors that cause high-throughput identification of methylated residues to be subject to a higher rate of false positives than other posttranslational modifications (Hart-Smith et al. 2015). This is largely because of the fact that several pairs of amino acid substitutions introduce the same 14 Da mass shift as methylation (for example, glycine to alanine). It is also common for samples treated with methanol to be chemically methylated at acidic residues. These potential artifacts can only be eliminated by careful evaluation of peptide fragmentation spectra. We recommend that researchers investigating a methylation site identified by high-throughput proteomics purify the protein from their particular biological system. LC-MS/MS can then be used to confirm that the modification exists and to measure the stoichiometry of mono-, di- and trimethylated forms.

To visualize cancer pathways that may be regulated by lysine methylation we mapped the list of methylated proteins onto cancer pathways annotated in the Kyoto Encyclopedia of Genes and Genomes (KEGG) (Kanehisa et al. 2015). Many core pathways are shared among these cancer pathways so we have visualized only the "prostate cancer" pathway (Fig. 3). Earlier we discussed how the MAPK pathway is regulated by methylation of MAP3K2. Methylation also occurs on core members of the pathway including growth factor receptors, SOS and Ras proteins, as well as in the androgen receptor pathway, the NF-кB pathway, on proteins that control cell cycle, and on p53.

With over 1000 methylated lysine residues reported so far, there is clearly a tremendous opportunity for future research. Techniques to identify these sites have existed for less than 3 years so many more methylated residues likely remain to be identified. Many of the nonhistone methylation sites studied in detail so far have revealed important new regulatory processes, and especially processes affecting cancer-related pathways. It will be of great scientific and clinical importance to understand the roles of nonhistone lysine methylation in normal physiology, to discover which sites and whether they act in cancer, and to map the pathways that they regulate.

\section{ACKNOWLEDGMENTS}

O.G. is supported by a grant from the National Institutes of Health (NIH) (RO1 CA172560). S.M.C. is supported by an NIH K99/R00 Pathway to Independence Award (K99CA190803). O.G. is a co-founder of EpiCypher.

\section{REFERENCES}

Abu-Farha M, Lanouette S, Elisma F, Tremblay V, Butson J, Figeys D, Couture JF. 2011. Proteomic analyses of the SMYD family interactomes identify HSP90 as a novel target for SMYD2. J Mol Cell Biol 3: 301-308.

Ambler RP, Rees MW. 1959. $\varepsilon-N$-Methyl-lysine in bacterial flagellar protein. Nature 184: 56-57.

Bannister AJ, Zegerman P, Partridge JF, Miska EA, Thomas JO, Allshire RC, Kouzarides T. 2001. Selective recognition of methylated lysine 9 on histone $\mathrm{H} 3$ by the HP1 chromo domain. Nature 410: 120-124.

Baudat F, Buard J, Grey C, Fledel-Alon A, Ober C, Przeworski M, Coop G, de Massy B. 2010. PRDM9 is a major determinant of meiotic recombination hotspots in humans and mice. Science 327: 836-840.

Biggar KK, Li SS. 2015. Non-histone protein methylation as a regulator of cellular signalling and function. Nat Rev Mol Cell Biol 16: 5-17.

Black JC, Van Rechem C, Whetstine JR. 2012. Histone lysine methylation dynamics: Establishment, regulation, and biological impact. Mol Cell 48: 491-507.

Cao XJ, Arnaudo AM, Garcia BA. 2013. Large-scale global identification of protein lysine methylation in vivo. Epigenetics 8: 477-485.

Carlson SM, Gozani O. 2014. Emerging technologies to map the protein methylome. J Mol Biol 426: 3350-3362.

Carlson SM, Moore KE, Sankaran SM, Reynoird N, Elias JE, Gozani O. 2015. A proteomic strategy identifies lysine methylation of splicing factor snRNP70 by the SETMAR enzyme. J Biol Chem 290: 12040-12047.

Casciello F, Windloch K, Gannon F, Lee JS. 2015. Functional role of G9a histone methyltransferase in cancer. Front Immunol 6: 487.

Cerami E, Gao J, Dogrusoz U, Gross BE, Sumer SO, Aksoy BA, Jacobsen A, Byrne CJ, Heuer ML, Larsson E, et al. 2012. The cBio cancer genomics portal: An open platform for exploring multidimensional cancer genomics data. Cancer Discov 2: 401-404.

Cho HS, Hayami S, Toyokawa G, Maejima K, Yamane Y, Suzuki T, Dohmae N, Kogure M, Kang D, Neal DE, et al. 2012. RB1 methylation by SMYD2 enhances cell cycle progression through an increase of RB1 phosphorylation. Neoplasia 14: 476-486.

Chuikov S, Kurash JK, Wilson JR, Xiao B, Justin N, Ivanov GS, McKinney K, Tempst P, Prives C, Gamblin SJ, et al. 
2004. Regulation of p53 activity through lysine methylation. Nature 432: 353-360.

Cloutier P, Lavallée-Adam M, Faubert D, Blanchette M, Coulombe B. 2013. A newly uncovered group of distantly related lysine methyltransferases preferentially interact with molecular chaperones to regulate their activity. PLoS Genet 9: e1003210.

Cloutier P, Lavallée-Adam M, Faubert D, Blanchette M, Coulombe B. 2014. Methylation of the DNA/RNA-binding protein Kin17 by METTL22 affects its association with chromatin. J Proteomics 100: 115-124.

Collins R, Cheng X. 2010. A case study in cross-talk: The histone lysine methyltransferases G9a and GLP. Nucleic Acids Res 38: 3503-3511.

Collins RE, Northrop JP, Horton JR, Lee DY, Zhang X, Stallcup MR, Cheng X. 2008. The ankyrin repeats of G9a and GLP histone methyltransferases are mono- and dimethyllysine binding modules. Nat Struct Mol Biol 15: 245-250.

Davydova E, Ho AY, Malecki J, Moen A, Enserink JM, Jakobsson ME, Loenarz C, Falnes P. 2014. Identification and characterization of a novel evolutionarily conserved lysine-specific methyltransferase targeting eukaryotic translation elongation factor 2 (eEF2). J Biol Chem 289: 30499-30510.

Derunes C, Briknarová K, Geng L, Li S, Gessner CR, Hewitt K, Wu S, Huang S, Woods VI, Ely KR. 2005. Characterization of the PR domain of RIZ1 histone methyltransferase. Biochem Biophys Res Commun 333: 925-934.

Dillon SC, Zhang X, Trievel RC, Cheng X. 2005. The SETdomain protein superfamily: Protein lysine methyltransferases. Genome Biol 6: 227.

Dong C, Wu Y, Yao J, Wang Y, Yu Y, Rychahou PG, Evers BM, Zhou BP. 2012. G9a interacts with Snail and is critical for Snail-mediated E-cadherin repression in human breast cancer. J Clin Invest 122: 1469-1486.

Du Y, Carling T, Fang W, Piao Z, Sheu JC, Huang S. 2001 Hypermethylation in human cancers of the RIZ1 tumor suppressor gene, a member of a histone/protein methyltransferase superfamily. Cancer Res 61: 8094-8099.

Eom GH, Kim K, Kim SM, Kee HJ, Kim JY, Jin HM, Kim JR, Kim JH, Choe N, Kim KB, et al. 2009. Histone methyltransferase PRDM8 regulates mouse testis steroidogenesis. Biochem Biophys Res Commun 388: 131-136.

Fnu S, Williamson EA, De Haro LP, Brenneman M, Wray J, Shaheen M, Radhakrishnan K, Lee SH, Nickoloff JA, Hromas R. 2011. Methylation of histone H3 lysine 36 enhances DNA repair by nonhomologous end-joining. Proc Natl Acad Sci 108: 540-545.

Fog CK, Galli GG, Lund AH. 2012. PRDM proteins: Important players in differentiation and disease. Bioessays 34: $50-60$.

Fog CK, Asmar F, Côme C, Jensen KT, Johansen JV, Kheir TB, Jacobsen L, Friis C, Louw A, Rosgaard L, et al. 2015. Loss of PRDM11 promotes MYC-driven lymphomagenesis. Blood 125: 1272-1281.

Forrester K, Almoguera C, Han K, Grizzle WE, Perucho M. 1987. Detection of high incidence of K-ras oncogenes during human colon tumorigenesis. Nature 327: $298-$ 303.

Fuchs SM, Krajewski K, Baker RW, Miller VL, Strahl BD. 2011. Influence of combinatorial histone modifications on antibody and effector protein recognition. Curr Biol 21: $53-58$.

Gaedcke J, Grade M, Jung K, Camps J, Jo P, Emons G, Gehoff A, Sax U, Schirmer M, Becker H, et al. 2010. Mutated KRAS results in overexpression of DUSP4, a MAP-kinase phosphatase, and SMYD3, a histone methyltransferase, in rectal carcinomas. Genes Chromosomes Cancer 49: 1024-1034.

Gao J, Aksoy BA, Dogrusoz U, Dresdner G, Gross B, Sumer SO, Sun Y, Jacobsen A, Sinha R, Larsson E, et al. 2013. Integrative analysis of complex cancer genomics and clinical profiles using the cBioPortal. Sci Signal 6: pl1.

Guo A, Gu H, Zhou J, Mulhern D, Wang Y, Lee KA, Yang V, Aguiar M, Kornhauser J, Jia X, et al. 2014. Immunoaffinity enrichment and mass spectrometry analysis of protein methylation. Mol Cell Proteomics 13: 372-387.

Hamamoto R, Furukawa Y, Morita M, Iimura Y, Silva FP, Li M, Yagyu R, Nakamura Y. 2004. SMYD3 encodes a histone methyltransferase involved in the proliferation of cancer cells. Nat Cell Biol 6: 731-740.

Hamamoto R, Saloura V, Nakamura Y. 2015. Critical roles of non-histone protein lysine methylation in human tumorigenesis. Nat Rev Cancer 15: 110-124.

Hart-Smith G, Yagoub D, Tay AP, Pickford R, Wilkins MR. 2015. Large-scale mass spectrometry-based identifications of enzyme-mediated protein methylation are subject to high false discovery rates. Mol Cell Proteomics 15: 989-1006.

Hayami S, Kelly JD, Cho HS, Yoshimatsu M, Unoki M, Tsunoda T, Field HI, Neal DE, Yamaue H, Ponder BA, et al. 2011. Overexpression of LSD1 contributes to human carcinogenesis through chromatin regulation in various cancers. Int J Cancer 128: 574-586.

Hayashi K, Yoshida K, Matsui Y. 2005. A histone H3 methyltransferase controls epigenetic events required for meiotic prophase. Nature 438: 374-378.

Herz HM, Garruss A, Shilatifard A. 2013. SET for life: Biochemical activities and biological functions of SET domain-containing proteins. Trends Biochem Sci 38: 621639.

Hohenauer T, Moore AW. 2012. The Prdm family: Expanding roles in stem cells and development. Development 139: $2267-2282$.

Hornbeck PV, Kornhauser JM, Tkachev S, Zhang B, Skrzypek E, Murray B, Latham V, Sullivan M. 2012. PhosphoSitePlus: A comprehensive resource for investigating the structure and function of experimentally determined post-translational modifications in man and mouse. $\mathrm{Nu}$ cleic Acids Res 40: D261-D270.

Hu M, Yao J, Cai L, Bachman KE, van den Brûle F, Velculescu V, Polyak K. 2005. Distinct epigenetic changes in the stromal cells of breast cancers. Nat Genet 37: 899-905.

Huang J, Berger SL. 2008. The emerging field of dynamic lysine methylation of non-histone proteins. Curr Opin Genet Dev 18: 152-158.

Huang J, Perez-Burgos L, Placek BJ, Sengupta R, Richter M, Dorsey JA, Kubicek S, Opravil S, Jenuwein T, Berger SL. 2006. Repression of p53 activity by Smyd2-mediated methylation. Nature 444: 629-632.

Huang J, Sengupta R, Espejo AB, Lee MG, Dorsey JA, Richter M, Opravil S, Shiekhattar R, Bedford MT, Jenuwein T, 
S.M. Carlson and O. Gozani

et al. 2007. p53 is regulated by the lysine demethylase LSD1. Nature 449: 105-108.

Huang J, Dorsey J, Chuikov S, Pérez-Burgos L, Zhang X, Jenuwein T, Reinberg D, Berger SL. 2010. G9a and Glp methylate lysine 373 in the tumor suppressor p53. J Biol Chem 285: 9636-9641.

Jakobsson ME, Moen A, Bousset L, Egge-Jacobsen W, Kernstock S, Melki R, Falnes P. 2013. Identification and characterization of a novel human methyltransferase modulating Hsp70 protein function through lysine methylation. J Biol Chem 288: 27752-27763.

Kanehisa M, Sato Y, Kawashima M, Furumichi M, Tanabe M. 2015. KEGG as a reference resource for gene and protein annotation. Nucleic Acids Res 44: D457-D462.

Kernstock S, Davydova E, Jakobsson M, Moen A, Pettersen S, Mælandsmo GM, Egge-Jacobsen W, Falnes P. 2012. Lysine methylation of VCP by a member of a novel human protein methyltransferase family. Nat Commun 3: 1038.

Komatsu S, Imoto I, Tsuda H, Kozaki KI, Muramatsu T, Shimada Y, Aiko S, Yoshizumi Y, Ichikawa D, Otsuji E, et al. 2009. Overexpression of SMYD2 relates to tumor cell proliferation and malignant outcome of esophageal squamous cell carcinoma. Carcinogenesis 30: 1139-1146.

Kubicek S, O'Sullivan RJ, August EM, Hickey ER, Zhang Q, Teodoro ML, Rea S, Mechtler K, Kowalski JA, Homon CA, et al. 2007. Reversal of H3K9me2 by a small-molecule inhibitor for the G9a histone methyltransferase. Mol Cell 25: 473-481.

Kunizaki M, Hamamoto R, Silva FP, Yamaguchi K, Nagayasu T, Shibuya M, Nakamura Y, Furukawa Y. 2007. The lysine 831 of vascular endothelial growth factor receptor 1 is a novel target of methylation by SMYD3. Cancer Res 67: 10759-10765.

Lachner M, O'Carroll D, Rea S, Mechtler K, Jenuwein T. 2001. Methylation of histone $\mathrm{H} 3$ lysine 9 creates a binding site for HP1 proteins. Nature 410: 116-120.

Laurent B, Ruitu L, Murn J, Hempel K, Ferrao R, Xiang Y Liu S, Garcia BA, Wu H, Wu F, et al. 2015. A specific LSD1/KDM1A isoform regulates neuronal differentiation through H3K9 demethylation. Mol Cell 57: 957970.

Levy D, Kuo AJ, Chang Y, Schaefer U, Kitson C, Cheung P, Espejo A, Zee BM, Liu CL, Tangsombatvisit S, et al. 2011. Lysine methylation of the NF-kB subunit RelA by SETD6 couples activity of the histone methyltransferase GLP at chromatin to tonic repression of NF- $\mathrm{BB}$ signaling. Nat Immunol 12: 29-36.

Liu F, Barsyte-Lovejoy D, Li F, Xiong Y, Korboukh V, Huang XP, Allali-Hassani A, Janzen WP, Roth BL, Frye SV, et al. 2013a. Discovery of an in vivo chemical probe of the lysine methyltransferases G9a and GLP. J Med Chem 56: 8931-8942.

Liu H, Galka M, Mori E, Liu X, Lin YF, Wei R, Pittock P, Voss C, Dhami G, Li X, et al. 2013b. A method for systematic mapping of protein lysine methylation identifies functions for HP1 $\beta$ in DNA damage response. Mol Cell 50: $723-735$.

Liu N, Zhang Z, Wu H, Jiang Y, Meng L, Xiong J, Zhao Z, Zhou X, Li J, Li H, et al. 2015. Recognition of H3K9 methylation by GLP is required for efficient establish- ment of H3K9 methylation, rapid target gene repression, and mouse viability. Genes Dev 29: 379-393.

Magnani R, Dirk LM, Trievel RC, Houtz RL. 2010. Calmodulin methyltransferase is an evolutionarily conserved enzyme that trimethylates Lys-115 in calmodulin. Nat Commun 1: 43.

Margueron R, Reinberg D. 2010. Chromatin structure and the inheritance of epigenetic information. Nat Rev Genet 11: $285-296$.

Mazur PK, Reynoird N, Khatri P, Jansen PW, Wilkinson AW, Liu S, Barbash O, Van Aller GS, Huddleston M, Dhanak D, et al. 2014. SMYD3 links lysine methylation of MAP3K2 to Ras-driven cancer. Nature 510: 283-287.

Małecki J, Ho AY, Moen A, Dahl HA, Falnes P. 2015. Human METTL20 is a mitochondrial lysine methyltransferase that targets the $\beta$ subunit of electron transfer flavoprotein (ETF $\beta$ ) and modulates its activity. J Biol Chem 290: 423434.

McCabe NR, Burnett RC, Gill HJ, Thirman MJ, Mbangkollo D, Kipiniak M, van Melle E, Ziemin-van der Poel S, Rowley JD, Diaz MO. 1992. Cloning of cDNAs of the MLL gene that detect DNA rearrangements and altered RNA transcripts in human leukemic cells with 11q23 translocations. Proc Natl Acad Sci 89: 11794-11798.

McCormick F. 2015. KRAS as a therapeutic target. Clin Cancer Res 21: 1797-1801.

Metzger E, Wissmann M, Yin N, Müller JM, Schneider R, Peters AH, Günther T, Buettner R, Schüle R. 2005. LSD1 demethylates repressive histone marks to promote androgen-receptor-dependent transcription. Nature 437: 436439.

Meyer C, Hofmann J, Burmeister T, Gröger D, Park TS, Emerenciano M, Pombo de Oliveira M, Renneville A, Villarese P, Macintyre E, et al. 2013. The MLL recombinome of acute leukemias in 2013. Leukemia 27: $2165-$ 2176.

Moore KE, Carlson SM, Camp ND, Cheung P, James RG, Chua KF, Wolf-Yadlin A, Gozani O. 2013. A general molecular affinity strategy for global detection and proteomic analysis of lysine methylation. Mol Cell 50: 444-456.

Morishita K, Parganas E, William CL, Whittaker MH, Drabkin H, Oval J, Taetle R, Valentine MB, Ihle JN. 1992. Activation of EVI1 gene expression in human acute myelogenous leukemias by translocations spanning 300400 kilobases on chromosome band 3q26. Proc Natl Acad Sci 89: 3937-3941.

Murray K. 1964. The occurrence of i $\varepsilon-N$-Methyl lysine in histones. Biochemistry 3: 10-15.

Myers S, Bowden R, Tumian A, Bontrop RE, Freeman C, MacFie TS, McVean G, Donnelly P. 2010. Drive against hotspot motifs in primates implicates the PRDM9 gene in meiotic recombination. Science 327: 876-879.

Nakakido M, Deng Z, Suzuki T, Dohmae N, Nakamura Y, Hamamoto R. 2015. Dysregulation of AKT pathway by SMYD2-mediated lysine methylation on PTEN. Neoplasia 17: 367-373.

Ng HH, Feng Q, Wang H, Erdjument-Bromage H, Tempst P, Zhang Y, Struhl K. 2002. Lysine methylation within the globular domain of histone $\mathrm{H} 3$ by Dot1 is important for telomeric silencing and Sir protein association. Genes Dev 16: $1518-1527$. 
Nishikawa N, Toyota M, Suzuki H, Honma T, Fujikane T, Ohmura T, Nishidate T, Ohe-Toyota M, Maruyama R, Sonoda T, et al. 2007. Gene amplification and overexpression of PRDM14 in breast cancers. Cancer Res 67: 96499657.

Nishioka K, Rice JC, Sarma K, Erdjument-Bromage H, Werner J, Wang Y, Chuikov S, Valenzuela P, Tempst P, Steward $\mathrm{R}$, et al. 2002. PR-Set7 is a nucleosome-specific methyltransferase that modifies lysine 20 of histone $\mathrm{H} 4$ and is associated with silent chromatin. Mol Cell 9: 1201-1213.

Northcott PA, Nakahara Y, Wu X, Feuk L, Ellison DW, Croul S, Mack S, Kongkham PN, Peacock J, Dubuc A, et al. 2009. Multiple recurrent genetic events converge on control of histone lysine methylation in medulloblastoma. Nat Genet 41: 465-472.

Ong S, Mann M. 2006. Identifying and quantifying sites of protein methylation by heavy methyl SILAC. Curr Protoc Protein Sci doi: 10.1002/0471140864.ps1409s46.

Ong SE, Mittler G, Mann M. 2004. Identifying and quantifying in vivo methylation sites by heavy methyl SILAC. Nat Methods 1: 119-126.

Paik WK, Paik DC, Kim S. 2007. Historical review: The field of protein methylation. Trends Biochem Sci 32: 146-152.

Parvanov ED, Petkov PM, Paigen K. 2010. Prdm9 controls activation of mammalian recombination hotspots. Science 327: 835.

Pasqualucci L, Compagno M, Houldsworth J, Monti S, Grunn A, Nandula SV, Aster JC, Murty VV, Shipp MA, Dalla-Favera R. 2006. Inactivation of the PRDM1/ BLIMP1 gene in diffuse large B cell lymphoma. J Exp Med 203: 311-317.

Petrossian TC, Clarke SG. 2011. Uncovering the human methyltransferasome. Mol Cell Proteomics 10: M110. 000976.

Pinheiro I, Margueron R, Shukeir N, Eisold M, Fritzsch C, Richter FM, Mittler G, Genoud C, Goyama S, Kurokawa M, et al. 2012. Prdm3 and Prdm16 are H3K9me1 methyltransferases required for mammalian heterochromatin integrity. Cell 150: 948-960.

Plotnikov A, Zehorai E, Procaccia S, Seger R. 2011. The MAPK cascades: Signaling components, nuclear roles and mechanisms of nuclear translocation. Biochim Biophys Acta 1813: 1619-1633.

Pradhan S, Chin HG, Estève PO, Jacobsen SE. 2009. SET7/9 mediated methylation of non-histone proteins in mammalian cells. Epigenetics 4: 383-387.

Prior IA, Lewis PD, Mattos C. 2012. A comprehensive survey of Ras mutations in cancer. Cancer Res 72: 2457-2467.

Rathert P, Dhayalan A, Murakami M, Zhang X, Tamas R, Jurkowska R, Komatsu Y, Shinkai Y, Cheng X, Jeltsch A. 2008. Protein lysine methyltransferase G9a acts on nonhistone targets. Nat Chem Biol 4: 344-346.

Rea S, Eisenhaber F, O'Carroll D, Strahl BD, Sun ZW, Schmid M, Opravil S, Mechtler K, Ponting CP, Allis CD, et al. 2000. Regulation of chromatin structure by site-specific histone H3 methyltransferases. Nature 406: 593-599.

Sakamoto LH, Andrade RV, Felipe MS, Motoyama AB, Pittella Silva F. 2014. SMYD2 is highly expressed in pediatric acute lymphoblastic leukemia and constitutes a bad prognostic factor. Leuk Res 38: 496-502.
Sampath SC, Marazzi I, Yap KL, Krutchinsky AN, Mecklenbräuker I, Viale A, Rudensky E, Zhou MM, Chait BT, Tarakhovsky A. 2007. Methylation of a histone mimic within the histone methyltransferase G9a regulates protein complex assembly. Mol Cell 27: 596-608.

Savickiene J, Treigyte G, Stirblyte I, Valiuliene G, Navakauskiene R. 2014. Euchromatic histone methyltransferase 2 inhibitor, BIX-01294, sensitizes human promyelocytic leukemia HL-60 and NB4 cells to growth inhibition and differentiation. Leuk Res 38: 822-829.

Schenk T, Chen WC, Göllner S, Howell L, Jin L, Hebestreit K, Klein HU, Popescu AC, Burnett A, Mills K, et al. 2012. Inhibition of the LSD1 (KDM1A) demethylase reactivates the all-trans-retinoic acid differentiation pathway in acute myeloid leukemia. Nat Med 18: 605-611.

Schubert HL, Blumenthal RM, Cheng X. 2003. Many paths to methyltransfer: A chronicle of convergence. Trends Biochem Sci 28: 329-335.

Shen C, Ipsaro JJ, Shi J, Milazzo JP, Wang E, Roe JS, Suzuki Y, Pappin DJ, Joshua-Tor L, Vakoc CR. 2015. NSD3-short is an adaptor protein that couples BRD4 to the CHD8 chromatin remodeler. Mol Cell 60: 847-859.

Shi Y. 2007. Histone lysine demethylases: Emerging roles in development, physiology and disease. Nat Rev Genet 8: 829-833.

Shi Y, Lan F, Matson C, Mulligan P, Whetstine JR, Cole PA, Casero RA. 2004. Histone demethylation mediated by the nuclear amine oxidase homolog LSD1. Cell 119: 941953.

Shi X, Kachirskaia I, Yamaguchi H, West LE, Wen H, Wang EW, Dutta S, Appella E, Gozani O. 2007. Modulation of p53 function by SET8-mediated methylation at lysine 382. Mol Cell 27: 636-646.

Shinkai Y, Tachibana M. 2011. H3K9 methyltransferase G9a and the related molecule GLP. Genes Dev 25: 781-788.

Sweis RF, Pliushchev M, Brown PJ, Guo J, Li F, Maag D, Petros AM, Soni NB, Tse C, Vedadi M, et al. 2014. Discovery and development of potent and selective inhibitors of histone methyltransferase g9a. ACS Med Chem Lett 5: 205-209.

Tachibana M, Sugimoto K, Fukushima T, Shinkai Y. 2001 Set domain-containing protein, G9a, is a novel lysinepreferring mammalian histone methyltransferase with hyperactivity and specific selectivity to lysines 9 and 27 of histone H3. J Biol Chem 276: 25309-25317.

Tachibana M, Sugimoto K, Nozaki M, Ueda J, Ohta T, Ohki M, Fukuda M, Takeda N, Niida H, Kato H, et al. 2002. G9a histone methyltransferase plays a dominant role in euchromatic histone $\mathrm{H} 3$ lysine 9 methylation and is essential for early embryogenesis. Genes Dev 16: 17791791.

Tachibana M, Ueda J, Fukuda M, Takeda N, Ohta T, Iwanari H, Sakihama T, Kodama T, Hamakubo T, Shinkai Y. 2005. Histone methyltransferases G9a and GLP form heteromeric complexes and are both crucial for methylation of euchromatin at H3-K9. Genes Dev 19: 815-826.

Takawa M, Cho HS, Hayami S, Toyokawa G, Kogure M, Yamane Y, Iwai Y, Maejima K, Ueda K, Masuda A, et al. 2012. Histone lysine methyltransferase SETD8 promotes carcinogenesis by deregulating PCNA expression. Cancer Res 72: 3217-3227. 
S.M. Carlson and O. Gozani

Tsukada Y, Fang J, Erdjument-Bromage H, Warren ME, Borchers CH, Tempst P, Zhang Y. 2006. Histone demethylation by a family of JmjC domain-containing proteins. Nature 439: 811-816.

Van Aller GS, Reynoird N, Barbash O, Huddleston M, Liu S Zmoos AF, McDevitt P, Sinnamon R, Le B, Mas G, et al. 2012. Smyd3 regulates cancer cell phenotypes and catalyzes histone H4 lysine 5 methylation. Epigenetics 7: 340343.

Vedadi M, Barsyte-Lovejoy D, Liu F, Rival-Gervier S, AllaliHassani A, Labrie V, Wigle TJ, Dimaggio PA, Wasney GA, Siarheyeva A, et al. 2011. A chemical probe selectively inhibits G9a and GLP methyltransferase activity in cells. Nat Chem Biol 7: 566-574.

Wang J, Lu F, Ren Q, Sun H, Xu Z, Lan R, Liu Y, Ward D, Quan J, Ye T, et al. 2011. Novel histone demethylase LSD1 inhibitors selectively target cancer cells with pluripotent stem cell properties. Cancer Res 71: 7238-7249.

Watanabe Y, Toyota M, Kondo Y, Suzuki H, Imai T, OheToyota M, Maruyama R, Nojima M, Sasaki Y, Sekido Y, et al. 2007. PRDM5 identified as a target of epigenetic silencing in colorectal and gastric cancer. Clin Cancer Res 13: $4786-4794$.

Watanabe T, Kobunai T, Yamamoto Y, Matsuda K, Ishihara S, Nozawa K, Iinuma H, Ikeuchi H, Eshima K. 2011. Differential gene expression signatures between colorectal cancers with and without KRAS mutations: Crosstalk between the KRAS pathway and other signalling pathways. Eur J Cancer 47: 1946-1954.

West LE, Gozani O. 2011. Regulation of p53 function by lysine methylation. Epigenomics 3: 361-369.

Wu H, Mathioudakis N, Diagouraga B, Dong A, Dombrovski L, Baudat F, Cusack S, de Massy B, Kadlec J. 2013. Molecular basis for the regulation of the H3K4 methyltransferase activity of PRDM9. Cell Rep 5: 13-20.

Yuan Y, Wang Q, Paulk J, Kubicek S, Kemp MM, Adams DJ, Shamji AF, Wagner BK, Schreiber SL. 2012. A small-molecule probe of the histone methyltransferase G9a induces cellular senescence in pancreatic adenocarcinoma. ACS Chem Biol 7: 1152-1157.

Yun M, Wu J, Workman JL, Li B. 2011. Readers of histone modifications. Cell Res 21: 564-578.

Zhang X, Tanaka K, Yan J, Li J, Peng D, Jiang Y, Yang Z, Barton MC, Wen H, Shi X. 2013. Regulation of estrogen receptor $\alpha$ by histone methyltransferase SMYD2-mediated protein methylation. Proc Natl Acad Sci 110: 1728417289.

Zheng YC, Ma J, Wang Z, Li J, Jiang B, Zhou W, Shi X, Wang X, Zhao W, Liu HM. 2015. A systematic review of histone lysine-specific demethylase 1 and its inhibitors. Med Res Rev 35: 1032-1071. 


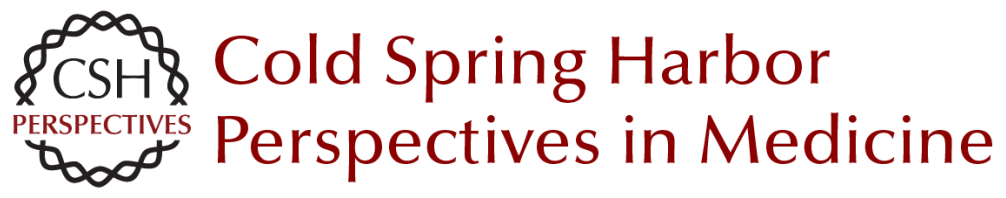

\section{Nonhistone Lysine Methylation in the Regulation of Cancer Pathways}

Scott M. Carlson and Or Gozani

Cold Spring Harb Perspect Med 2016; doi: 10.1101/cshperspect.a026435 originally published online August 31, 2016

\section{Subject Collection Chromatin Deregulation in Cancer}

\section{Mixed-Lineage Leukemia Fusions and Chromatin in Leukemia \\ Andrei V. Krivtsov, Takayuki Hoshii and Scott A. Armstrong}

Targeting Cancer Cells with BET Bromodomain Inhibitors

Yali Xu and Christopher R. Vakoc

The Role of Nuclear Receptor-Binding SET

Domain Family Histone Lysine Methyltransferases

in Cancer

Richard L. Bennett, Alok Swaroop, Catalina Troche, et al.

SETting the Stage for Cancer Development:

SETD2 and the Consequences of Lost Methylation Catherine C. Fahey and lan J. Davis

ATRX and DAXX: Mechanisms and Mutations Michael A. Dyer, Zulekha A. Qadeer, David Valle-Garcia, et al.

DNMT3A in Leukemia

Lorenzo Brunetti, Michael C. Gundry and Margaret A. Goodell

Oncogenic Mechanisms of Histone H3 Mutations Daniel N. Weinberg, C. David Allis and Chao Lu

Nonhistone Lysine Methylation in the Regulation of Cancer Pathways

Scott M. Carlson and Or Gozani
TET2 in Normal and Malignant Hematopoiesis Robert L. Bowman and Ross L. Levine

Long Noncoding RNAs: At the Intersection of Cancer and Chromatin Biology Adam M. Schmitt and Howard Y. Chang

DNA Hypomethylating Drugs in Cancer Therapy Takahiro Sato, Jean-Pierre J. Issa and Patricia Kropf

The Chromodomain Helicase DNA-Binding Chromatin Remodelers: Family Traits that Protect from and Promote Cancer Alea A. Mills

Exploitation of EP300 and CREBBP Lysine

Acetyltransferases by Cancer Narsis Attar and Siavash K. Kurdistani

Histone Lysine Demethylase Inhibitors Ashwini Jambhekar, Jamie N. Anastas and Yang Shi

Cohesin Mutations in Cancer Magali De Koninck and Ana Losada

MLL3/MLL4/COMPASS Family on Epigenetic Regulation of Enhancer Function and Cancer Christie C. Sze and Ali Shilatifard

For additional articles in this collection, see http://perspectivesinmedicine.cshlp.org/cgi/collection/ 